\title{
Ethnicity, Epistemological Beliefs, Thinking Skills and Concept Understanding in Chemistry
}

\author{
Lourdes B. Filoteo $^{1}$, Vivien M.Talisayon ${ }^{2}$ and Marlene B. Ferido ${ }^{3}$ \\ CSM-WMSU, Normal Road, Baliwasan, Zamboanga City ${ }^{1}$ \\ CED, U.P. Diliman, Quezon City ${ }^{2}$ \\ NISMED, U.P. Diliman, Quezon City ${ }^{3}$ \\ Philippines
}

\begin{abstract}
The study assessed students' epistemological beliefs, examined the effectiveness of epistemological enhanced instruction (EEI); and influenced of these beliefs on critical thinking and chemistry concept understanding. It used the quasi-experimental pretest-posttest two-group design. Two intact classes of first year nursing students enrolled in chemistry at CSM, WMSU, Zamboanga City, Philippines were randomly selected and grouped as EEI and LMI. Findings showed that the epistemological beliefs prevalent among students were sophisticated, theoretical, empirical and perceptual beliefs in the nature of chemistry knowledge. Findings further reveal, that the students held simple like perceptual and complex beliefs (sophisticated, theoretical, and empirical) about the nature of knowledge. On beliefs of knowledge source, students held external, social, and justification of knowledge but not internal beliefs. Ethnicity did not influence students' epistemological beliefs. Students in EEI showed significant difference in epistemological beliefs, particularly for nä̈ve, perceptual, external, and justification of knowledge beliefs. Students' empirical, theoretical and internal beliefs are significant predictors of conceptual understanding and internal source belief a significant negative predictor of conceptual understanding. Theoretical beliefs are predictors of critical thinking. The overall critical thinking skills score is a predictor of conceptual understanding. Among the critical thinking skills, inference best predicts conceptual understanding.
\end{abstract}

\section{Introduction}

A substantial body of research indicates that science educators need to focus on a related but somewhat different set of beliefs to facilitate learning for understanding. These are the epistemological beliefs, pertaining to philosophical views and theories that students have about the nature and acquisition of scientific knowledge. These are conceptions of learning and knowledge that affects how student approach and evaluate information and problems faced in both the classroom and daily life [7]. Theories of these beliefs address the nature of knowledge (chemistry) and the nature of knowing and thus provide a standard for our understanding of learning Hofer and Pintrich [6]. It affects students' learning, academic performance comprehension and is domainspecific [4]. Moreover, it offers insights into effective teaching Hofer, Sandoval found little work examined how such beliefs influence students' efforts to learn science [6] [18]. Pintrich suggested that teaching designs/strategies that examine the influence of personal beliefs on academic outcomes be introduced for the students to develop in them to think critically through reflecting on 'how do they know on what they know' and why they believe, Reddish \& Hammer [15] [17]. Innovations and new designs of chemistry teaching strategies that involved students beliefs be then introduced in an attempt to enhance not only students' understanding of chemistry concepts but also develop them to think critically through reflecting on how do they know what they know. Science educators need also to consider the ethnic and cultural backgrounds of the students they cater. Knowledge of the existence of these beliefs among ethnic groups must also be considered vis-à-vis the development of critical thinking and concept understanding. Thus, this study assessed the epistemological beliefs of students of different ethnic groups, examined whether these beliefs would differ after instruction and determine which of these beliefs contribute to the development of their critical thinking skills and conceptual understanding in chemistry. 


\section{Statement of the Problem}

This study assessed the epistemological beliefs in chemistry of students of diverse ethnic groupsChavacanos, Tausugs and Visayans- examined which of the students' epistemological beliefs influenced the development of students' critical thinking skills and understanding of chemistry concepts. Specifically, the study sought to answer the following questions:

1. What are the epistemological beliefs prevalent among students enrolled in Chemistry in terms of:

a) nature of knowledge b) nature of knowing
(1) theoretical
(1) internal
(2) perceptual
(2) external
(3) empirical
(3) social
(4) naïve
(5) sophisticated
(4) justification of knowing

2. Do these epistemological beliefs differ based on students' ethnicity, classified as follows:
a. Chavacano
b. Tausug
c. Visayan

3. Is there a difference in the epistemological beliefs of students exposed to epistemologicalenhanced instruction and those of students exposed to the traditional method of instruction?

4. Do students' epistemological beliefs in chemistry influence their critical thinking skills?

5. Do students' epistemological beliefs in chemistry and critical thinking skills positively predict their understanding of chemistry concepts?

\section{Significance of the Study}

The results of this study will provide baseline data on students' epistemological beliefs in chemistry, guide science educators/teachers and curriculum designers to consider students' epistemological beliefs in chemistry in their goals not only the development of the students' cognitive aspect of learning but the development of students' epistemological beliefs as well. It will offer new direction for chemistry teachers to use the epistemologically-enhanced instruction as an alternative method, to the usual traditional way of teaching chemistry concepts as these beliefs appear to influence students' critical thinking skills and concept understanding. The developed model (EEI) challenges the students to inquire, think, and evaluate their thoughts critically and to predict, infer, collaborate, analyze, evaluate, summarize, make conclusions and in turn lead to change in the students' beliefs about the nature of chemistry knowledge and nature of knowing chemistry. Consequently, their skill to think critically and understanding of concepts will be developed and improved. This study could also provide chemistry teachers insights in terms of focusing on students' cognitive aspect of learning or knowing chemistry but also knowledge of the existence of these beliefs among diverse ethnic students about chemistry can help them plan and direct their lessons based on students' epistemological beliefs vis-à-vis the development of their critical thinking skills and understanding of chemistry concepts.

\section{Methodology}

\subsection{Research Design}

The study is a combination of qualitative and quantitative research designs. On the qualitative part, the epistemological beliefs of students were assessed using a researcher-developed tool and results were used to determine which among the beliefs influence their thinking skills and concept understanding in chemistry. The quantitative research design used a quasi-experimental a pretest- posttest two-group design, as follows:

$$
\begin{array}{cccc}
\text { Group 1 } & \mathrm{O}_{1} \mathrm{O}_{2} \mathrm{O}_{3} & \mathrm{X}_{1} & \mathrm{O}_{4} \mathrm{O}_{5} \mathrm{O}_{6} \\
\text { Group 2 } & \mathrm{O}_{1} \mathrm{O}_{2} \mathrm{O}_{3} & \mathrm{X}_{2} & \mathrm{O}_{4} \mathrm{O}_{5} \mathrm{O}_{6} \\
\mathrm{X} 1= & \text { epistemologically-enhanced instruction } \\
\mathrm{X}_{2}= & \text { lecture method of instruction }
\end{array}
$$

\subsection{The Sample}

The samples are nursing students enrolled in Chemistry 101. From 10 sections, two intact classes were randomly selected to make the EEI and the LMI groups. EEI group was the treatment group. Eighty students in the two classes whose age ranges from 1617 years old completed the pre-post test assessment. The classes are made up of three different ethnic groups -Chavacano, Tausugs and Visayans.

\subsection{Instruments}

The instruments used in this study are: WatsonGlaser Critical Thinking Appraisal, (WGCTA), a standardized test; a researcher-made Conceptual Understanding Test (CUT), and a researcherdeveloped instrument 5-point Likert Scale Epistemological Beliefs Questionnaire in Chemistry (EBCQ), and Students' Profile Questionnaire and Interview Guide.

\subsection{Epistemological-Enhanced Instruction}

The design of this teaching intervention is the same as the LMI, except that this design is 
epistemologically-enhanced. This involved the following: a) Pre-Demonstration activity b) Demonstration Proper c) Post-Demonstration Lecture d) Summary and conclusion.

\section{Results and Discussion}

\subsection{Prevalent Epistemological Beliefs amongst Students}

In determining the students' prevalent epistemological beliefs in chemistry, the mean rating scores and standard deviations for each subscale were calculated. The new range used to determine the students' level of agreement for a given item in the questionnaire is as follows: 1.0-1.79; 1.8-2.59; 2.63.39 low/weak or uncertain; 3.4-4.19; and 4.2-5.0 high/ strong. Figures 1 and 2 show the prevalent epistemological beliefs of students in chemistry before and after intervention respectively.

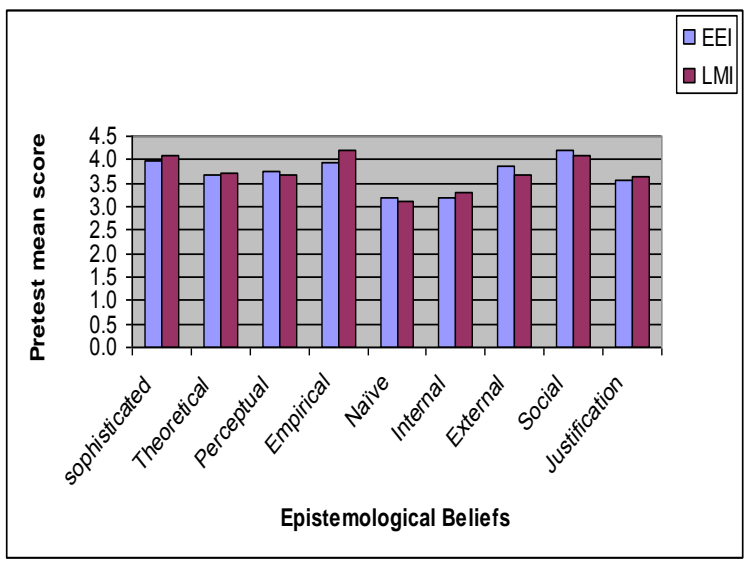

\section{Figure 1 \\ Epistemological beliefs in chemistry of EEI and LMI groups before intervention}

The assessed epistemological beliefs prevalent among the students before intervention are sophisticated, theoretical, empirical and perceptual as to nature of chemistry knowledge and external, social as beliefs sources and justification of knowledge of knowing chemistry. However, these beliefs remained the same but their level of agreement had been enhanced after intervention. This implies that students in both groups strongly believe in their knowledge on the nature of chemistry and nature of knowing. These are their philosophical views on the different concepts of chemistry discussed and teachers can integrate in their teaching episodes questions involving these beliefs. The naïve and internal source beliefs are not evident among the students. Following are some items on the beliefs scale questionnaire that students had strongly demonstrated. In the nature of chemistry knowledge, the students held this beliefs known as sophisticated, e.g. a) knowing chemistry is necessary because it affects our lives. b) what I know about chemistry is not solely based on content but also through interpreting the world. It can be inferred that students strongly believed that chemistry is connected to their lives outside the classroom or natural world as what Elby termed as "reality link" [3]. Moreover, students held these theoretical beliefs when they strongly agreed to this statement: a) compounds found in nature are numerous due to chemical bonding.

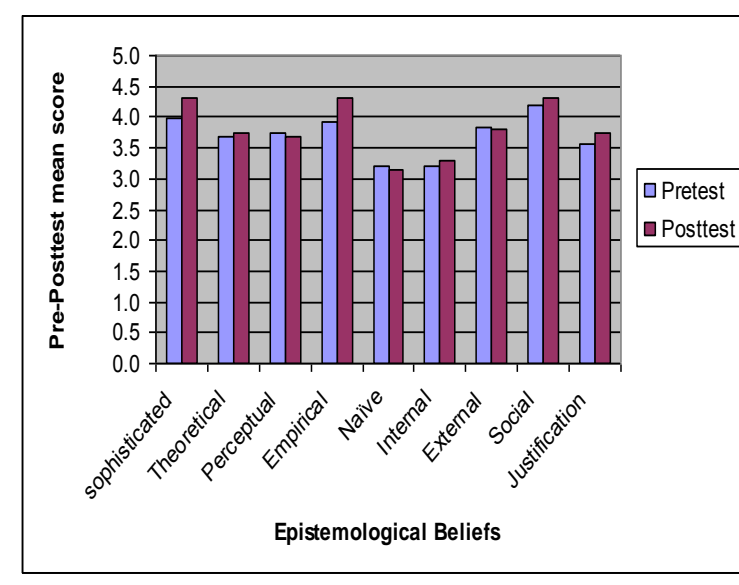

\section{Figure 2 \\ Epistemological beliefs of students in chemistry pre post intervention}

b) chemists follow a recipe-like method in doing investigation. The concept of bonding is abstract, students can only imagine and create images and make inferences about chemical bond where conceptualization is supported by a theory. In the second item, students strongly held this belief as this is what may have been practiced in the classroom in a "cookbook" fashion, where students follow the direction of an experiment and get the "right" answer and perhaps got the thinking that getting the 'right' answer relies on proper employment of the scientific method in Millwood and Sandoval [14]. Such student's assertion of beliefs should not be encouraged and must be corrected by exposing students to authentic situations, and showing them how scientists work. Students held these perceptual beliefs: a) chemistry is like forming opinions; b) chemistry is a process of accumulating facts about the chemical world c) my chemistry knowledge may be different from my classmates. Students kept these beliefs probably because this is what they apparently sensed in their surrounding world and experienced in their course of study, which becomes rooted in their minds. However, these beliefs do not promote in the students' 
mind the dynamic nature of science. Students were uncertain with one item, "Chemistry knowledge is an array of unconnected facts and concepts. This uncertainty may be attributed to the lack of understanding of the science knowledge in particular chemistry that they could not agree or disagree with the statement. Nevertheless, they can be made to understand that the nature of chemistry knowledge like all other scientific knowledge is not simply forming opinions, neither a process of accumulating facts nor an array of unconnected facts and concepts, but, it is dynamic, ever changing and a continuing process of knowing and constructing knowledge about the chemical world, and so, as new facts or theories emerge, old ones are discarded. Likewise, students can be made to understand that chemistry knowledge is an integration of interrelated networks of scientific knowledge. Furthermore, students strongly demonstrated the following empirical beliefs: a) knowledge in chemistry is acquired thru experiments and observation; b) chemistry deals with observations about matter and its behavior. These suggest that students may have been exposed to the use of process skills like doing observations, conducting experiments in the course of their study. Hence, they strongly believed that chemistry knowledge is capable of empirical test. This was further confirmed when students were interviewed where this question was asked: "What are your beliefs about how you acquired your knowledge in chemistry?'Mostly, answered, knowledge in chemistry can be achieved thru observations, doing activities, and experiment. Indeed, it can be deduced that the students' exposure and learning experience in their formal science education do contribute to their knowledge on the nature of chemistry. These findings concur with that of Kim's where she reported that students' exposure to the use of experiment during their course of study has led students to affirm their beliefs about the testable nature of science (chemistry) knowledge [9].

On the nature of knowing chemistry, students held these external sources of knowledge beliefs: a) I can understand a concept in chemistry better by referring to other chemistry journals and magazines; b) chemistry knowledge is built through hands on activities and observations in the laboratory class; and that their c) knowledge in chemistry comes from books. On social sources of knowledge beliefs, students strongly agreed that; a) chemistry knowledge is learned best through interaction with the whole class; b) knowledge of chemistry is best constructed when an actual demonstration is done in the class. For these sources of knowing chemistry, the students did not only indicate involving themselves in building on their own idea or doing observations on their own, but, also, in interacting with their peers or other groups, and participating in actual demonstration. When students were asked, "what have been the most important sources of chemistry knowledge that influenced the acquisition of what you know in chemistry?" their responses were a combination of external and social sources. Six out of nine $(67 \%)$ interviewed students responded that books were their most important source that affect their knowing and constructing chemistry knowledge. Others $(33 \%)$ responded class discussion, demonstration, and experiment and the teacher as the knowledge authority. These findings reveal that students' chemistry knowledge is built mostly through external sources and social interaction with peers, discussions, and sharing of ideas, demonstrations and experiments with a group. Students manifest beliefs that dovetail with the social constructivist's view that "people only attain knowledge of their surrounding by dealing with others, that is, in social discourse [1].

As to justification of knowledge beliefs, student strongly agreed that: a) true knowledge in chemistry can be arrived at when it concurs with other beliefs, and b) true knowledge in chemistry can be attained through consensus as ways of justifying for knowing chemistry. These results suggest that whether or not students know something about a concept depends on what the groups' decision is. For instance, answers on students' work sheets on justification of knowing the chemistry topics discussed revealed that one knows if one's prediction is correct or if it is similar to that of a peer. This further indicates that students rely on their peers and others in developing or in the construction of their chemistry knowledge. This reliance on their peers somehow validates or affirms their knowledge and understanding about a concept in chemistry. Most of the students as observed rely on external and social sources of knowing chemistry to justify their knowledge claim. For instance, on external sources as a justification of knowing, students rely more on their teachers, textbooks and social sources on class activities, like discussions, demonstrations and experiment. One knows when one can explain the topic to others and when they agree, say- "So my prediction is correct." This finding is in accord with the view of Carspecken in Radigan that students in stating their sources of knowledge is somehow a justification of their knowledge claim which aim to gain consensus from a cultural group as part of human communication [16]. On the other hand, naïve beliefs on the nature of chemistry knowledge and internal source beliefs are not evident among the students. For naïve beliefs, students responded with uncertainty on these items: a) what is in chemistry books are always right; b) A vast amount of chemistry knowledge is certain; c) What my chemistry teacher had taught is what I believe; d) I believe my chemistry teacher knows all the knowledge about chemistry. Elby termed 
students' internal source beliefs as independent source of knowing science [3]. The students answered the following items with uncertainty: a) my chemistry knowledge is earned through self-introspection, my knowledge in chemistry is built through reflection; $b$ ) working alone in chemistry problem lead to better understanding of concepts; and c) my knowledge in chemistry is based on my prior knowledge and experience. These results show that students were undecided and that they could neither agree nor disagree on these items. The students' answers on the work sheets on chemistry topics covered in the class confirmed that most of them did not rely on their internal source. Maybe, these students either relied more on the external sources of chemistry knowledge construction or simply because they lacked the experiences, or their thoughts are at odds with what they perceived in their surrounding world; thus they could not decide.

\subsection{Epistemological Beliefs in Chemistry and Ethnicity}

Table1 shows the descriptive statistics of the epistemological beliefs in chemistry of students by ethnicity.

Table 1

Descriptive statistics of the epistemological beliefs in chemistry by ethnicity

\begin{tabular}{|c|c|c|c|}
\hline Ethnicity & $\mathrm{N}$ & Mean & S.D. \\
\hline Chavacanos & 37 & 159.97 & 13.00 \\
\hline Tausugs & 22 & 156.55 & 9.61 \\
\hline Visayans & 21 & 156.48 & 11.98 \\
\hline Total & 80 & 158.11 & 11.87 \\
\hline
\end{tabular}

Results reveal that among the three groups, the Chavacanos yielded a higher pretest mean score than the Tausugs and Visayans. Analysis of variance (ANOVA) was run to determine whether the epistemological beliefs mean scores of these three groups by ethnicity differ. F-test analysis (Table 2) shows that the epistemological beliefs pretest mean scores of the three ethnic groups are not significantly different. This means that the three groups of students are comparable in terms of their epistemological beliefs as to- nature of chemistry knowledge and nature of knowing chemistry.
Table 2

ANOVA on the pretest mean scores of three ethnic groups in the epistemological beliefs in chemistry questionnaire

\begin{tabular}{|l|l|l|l|l|l|}
\hline & SS & df & $\mathrm{X}^{2}$ & $\begin{array}{l}\mathrm{F}- \\
\text { value }\end{array}$ & $\begin{array}{l}\mathrm{p}- \\
\text { value }\end{array}$ \\
\hline $\begin{array}{l}\text { Between } \\
\text { groups }\end{array}$ & 238.32 & 2 & 119.16 & & \\
\cline { 1 - 4 } $\begin{array}{l}\text { Within } \\
\text { groups }\end{array}$ & 10899.67 & 77 & 141.55 & .84 & .44 \\
\cline { 1 - 5 } Total & 11137.99 & 79 & & & \\
\hline
\end{tabular}

Table 3 shows the descriptive statistics of the three groups. Among the three groups- Chavacanos still yielded a higher posttest mean score than the Visayans and Tausugs. It is hypothesized that the three groups differ in their epistemological beliefs. However, F-test results in the English component in the entrance examination of the three groups showed that the $\mathrm{F}$ value $=6.7$ is highly significant at $p=.002$ which suggests that the three ethnic groups were not comparable in terms of English background before intervention.

Table 3

Descriptive statistics of the students' epistemological beliefs in chemistry posttest scores by ethnicity

\begin{tabular}{|l|l|l|l|}
\hline Ethnicity & $\mathrm{N}$ & Mean & S. D. \\
\hline Chavacanos & 37 & 163.1357 & 12.9361 \\
\hline Tausug & 22 & 161.4545 & 10.6140 \\
\hline Visayans & 21 & 161.6667 & 16.0072 \\
\hline Total & 80 & 162.2875 & 13.0084 \\
\hline
\end{tabular}

Analysis of covariance (ANCOVA) was run and results (Table 4) revealed that there is no significant difference in the mean rating posttest score of students of the three ethnic groups- Chavacano, Tausugs, and Visayans at the .05 level of significance using English as covariate. The null hypothesis of no significant difference in the beliefs among the three groups cannot be rejected. This means that the three ethnic groups did not differ in the epistemological beliefs in both categories: nature of chemistry knowledge and of knowing chemistry. The result suggests that although the students differed in their ethnic affiliations and in the dialects spoken at home, they might have had the same experience and exposure in their formal 
education on the nature of chemistry knowledge and nature of knowing chemistry.

\section{Table 4 \\ Results of ANCOVA on students' epistemological beliefs in chemistry posttest scores}

\begin{tabular}{|l|l|l|l|l|c|}
\hline Source & SS & $\mathrm{df}$ & $\mathrm{X}^{2}$ & $\mathrm{~F}$ & $\mathrm{p}$ \\
\hline $\begin{array}{l}\text { Corrected } \\
\text { Model }\end{array}$ & 70.55 & 3 & 23.52 & .134 & .939 \\
\hline Intercept & $\begin{array}{l}66236.8 \\
2\end{array}$ & 1 & $\begin{array}{l}66236 \\
.8\end{array}$ & 78.6 & .000 \\
\hline $\begin{array}{l}\text { English } \\
\text { Score }\end{array}$ & 20.61 & 1 & 20.61 & .118 & .732 \\
\hline Ethnicity & 27.71 & 2 & 13.85 & .079 & .924 \\
\hline Error & 3292.8 & 76 & 174.9 & & \\
\hline $\begin{array}{l}\text { Total } \\
212034\end{array}$ & 80 & & & \\
\hline $\begin{array}{l}7 . \\
\text { Corrected } \\
\text { Total }\end{array}$ & 13368.4 & 79 & & & \\
\hline
\end{tabular}

This indicates that ethnicity did not influence the students' epistemological beliefs. This is in agreement with the responses of the students of the different ethnic groups' gathered from the questionnaire and from the answers in their work sheets regarding on their empirical beliefs on the nature of chemistry knowledge, that indicate that they most strongly agreed that: a) knowledge in chemistry is acquired thru experiments and observations, $b$ ) chemistry deals with observations about matter and its behavior and c) books. These students of the different groups were exposed to the same program of activity and were tasked to observe experiment and use books as sources of knowledge. These became tools for building on their knowledge beliefs. This implies that what the students experienced or in class influenced their beliefs. These findings are in accord with Tsai and Jheng, Johnson, and Anderson they claimed that personal epistemological beliefs either in general or in science may come mainly from formal schooling or formed within the context of individuals' academic experiences [8] [20]. This further implies that students' epistemological beliefs in chemistry are formed within the milieu of their formal academic experiences.

\subsection{Students Epistemological Beliefs in Chemistry after Intervention}

Table 5 shows a significant $t$-value ( $p>.01)$ indicating a significant difference in the mean posttest score between the EEI and the LMI groups on their epistemological beliefs in favor of the EEI group. This result means that the use of EEI developed the students' understanding of their beliefs about the nature of chemistry knowledge and of knowing chemistry more than the Lecture Method of Instruction (LMI). So, which among these beliefs do students differ in the nine subscales in the epistemological beliefs scale? Using ANCOVA, results show that of the nine subscales in the

\section{Table 5 \\ Independent t-test results of the students' epistemological beliefs in chemistry after intervention}

\begin{tabular}{|l|l|l|l|l|}
\hline Group & Mean & SD & $\begin{array}{l}\mathrm{t}- \\
\text { value }\end{array}$ & $\begin{array}{l}\mathrm{p}- \\
\text { value }\end{array}$ \\
\hline EEI & 166.1250 & 13.6121 & 2.746 & .007 \\
\hline LMI & 158.4500 & 11.2818 & & \\
\hline
\end{tabular}

epistemological beliefs scale, four beliefs subscales yielded an F-value that show significant difference in the posttest mean scores of the two groups. These are the perceptual $\mathrm{F}=9.228(\mathrm{p}<.003)$ and naïve beliefs, $\mathrm{F}=4.935 \quad(\mathrm{p}<.000)$ of the nature of chemistry knowledge and the external source belief, $\mathrm{F}=$ $4.807(\mathrm{p}<.031)$ and justification of knowledge, $\mathrm{F}=$ 7.887 ( $\mathrm{p}<.006)$ of the nature of knowing. The students exposed to the EEI differ significantly from those of the LMI group in their naïve and perceptual beliefs and external and justification beliefs of knowing chemistry. Nonetheless, the students do not differ as to sophisticated, theoretical, and empirical beliefs in the nature of chemistry knowledge and in internal and social beliefs as sources of knowing chemistry. These indicate that students may have the same exposure and experience in their previous science courses hence there is an emerging similarity in the factor structure of these non-significant beliefs. Moreover, these students may be exposed to the same mandated curricular offerings of the government. The four subscales, naïve, perceptual, external and justification beliefs appeared to contribute to the significant difference in the posttest scores of the two groups using the entrance science score as the covariate. Results imply that the teaching intervention which is epistemological and interactive may have contributed to the difference in the students' beliefs and made them aware of these beliefs about the nature of chemistry knowledge and knowing. For example, in terms of naïve beliefs, the items in the questionnaire where the students lie between the low and upper end of the continuum characterized as uncertain are: a) 
what is in the chemistry book is always right; b) what my chemistry teacher had taught is what I believe; and c) I believe my chemistry teacher knows all the knowledge about chemistry; and d) a vast amount of chemistry knowledge is certain. Perhaps students may have come to know that what is in chemistry books may not always be right for these are works of men or women who are free to make mistakes and chemistry knowledge is not certain or fixed but tentative or is changing and evolving and the teacher implicitly provides information and structure, experiences that form the basis of their belief. Moreover, chemistry knowledge is developed on one's own learning experience and thus, their epistemological beliefs about nature of chemistry and knowing. With respect to perceptual beliefs, chemistry knowledge is not simply forming opinions or simply saying it is an accumulation of facts. Students need to know that chemistry knowledge is developed through observing, making hypothesis, or testing, and not just formed based on one's own view and it is not an accumulation of facts, but a continuing process of knowing about the chemical world that old theories are discarded as new findings appear or discoveries made and new theories emerge. On external beliefs, student need to know that chemistry is not simply based on intuition or self introspection. They can be made o understand that chemistry knowledge is not acquired through one's own instinct or to examine one's own self. Students have to investigate and observe that the surrounding world where one lives is a vast reservoir of chemical knowledge. Moreover, students may be made to understand that the classroom also presents actual realities since chemistry knowledge is developed through the interpretation of data and negotiating meaning from classroom experiences. As to justification of knowing chemistry, the students aside from relying on consensus and on the beliefs of others, they can justify knowledge in chemistry through observation, experiments and data, and must be made aware that through these processes, theories are developed. Lederman asserts that science, particularly chemistry, is theory-laden [11]. In the interview conducted on justification of their knowing chemistry, students were asked, "How do you know when you have learned and understood concepts in chemistry? What are your indicators?" the common response among the students interviewed was: I have learned or understood chemistry concepts when- I can explain or discuss the concept with my classmate; or I can share my chemistry ideas with others, some responded: I can answer questions pertaining to the topic and while others answered: I can apply this knowledge to everyday activities. Class observations also revealed that the students have varied ideas posited on justifying their knowing of chemistry. Nevertheless, students need to know that justification of knowing chemistry is not simply according to what one can explain, discuss, share or apply but, it is derived through evidence, logic and reason Hofer and Pintrich [7]. Sandoval suggested that students are encouraged to justify their knowledge claims with available data and consistency with other theories [18]. The significant contribution in the change of these beliefs in the students may be then ascribed to the interactive nature of the teaching intervention used where their epistemic views are invoked through the epistemological questions that are explicitly elicited from them. These findings are supported by several studies. Leach, Hind and Ryder in their study concluded that some students did improve their ability to articulate some basic epistemological ideas and were able to draw upon a wide range of perspective about the nature of science in particular context [10].

\subsection{Epistemological Beliefs and critical thinking skills}

Table 6 illustrates the multiple regression results with the nine subscales of the beliefs in chemistry as

Table 6

Multiple regression results: Influence of students' epistemological beliefs in chemistry of the nine subscales on critical thinking skills

\begin{tabular}{|l|l|l|l|}
\hline & $\beta$ & $\mathrm{t}$-value & $\mathrm{p}$-value \\
\hline (Constant) & & 3.833 & .000 \\
\hline Empirical & .089 & .704 & .484 \\
\hline Theoretical & .415 & 3.231 & .002 \\
\hline sophisticated & -.096 & -.697 & .488 \\
\hline Perceptual & -.133 & -1.053 & .296 \\
\hline Naïve & -.168 & -1.313 & .193 \\
\hline Internal & -.039 & -.324 & .747 \\
\hline External & -.018 & -.137 & .892 \\
\hline social & .201 & 1.422 & .160 \\
\hline Justification & -.045 & -.360 & .720 \\
\hline
\end{tabular}

\begin{tabular}{|l|l|l|l|}
\hline \multicolumn{1}{|c|}{$\mathrm{R}$} & $\mathrm{R}^{2}$ & F-value & $\mathrm{p}$-value \\
\hline .416 & .173 & 1.630 & .124 \\
\hline
\end{tabular}

the independent variable and critical thinking as the dependent variable. The ANOVA had an F- value of 1.630 which tells that the model is not significant at $\mathrm{p}<.05$. Of the nine subscales of the students' beliefs in chemistry, however, only the students' theoretical beliefs score appears to contribute to students' critical thinking scores. When multiple regression was run further, where theoretical beliefs subscale score as the 
single independent variable and critical thinking as the dependent variable, theoretical beliefs (Table 7) yielded a significant regression coefficient, $\beta=0.313$ $(\mathrm{p}<.005)$. This means that the students' theoretical beliefs scores significantly and positively contribute to the development of critical thinking skills. It can be inferred that the teaching intervention employed that engaged students to reflect where their epistemic views are elicited as they explain and justify their reasons for knowing concepts in chemistry that are consistent with established theories may have contributed to such. Furthermore, such kind of teaching intervention enables the students to become more actively engaged in a lecture and provide unique opportunities for critical thinking. This finding is in accord with Sandoval and Tolhurst [18] [19]. This implies that teachers can design instruction that grants students opportunities to construct theoretically or content-based knowledge to enhance students' critical thinking skills.

Table 7

Multiple regression results: Theoretical beliefs subscale posttest score as predictor of critical thinking skill

\begin{tabular}{|c|c|c|c|}
\hline & $\beta$ & $\mathrm{t}-\mathrm{value}$ & $\mathrm{p}$-value \\
\hline (Constant) & & 9.933 & .000 \\
\hline $\begin{array}{c}\text { Theoretical } \\
\text { (Post) }\end{array}$ & .313 & 2.195 & .005 \\
\hline
\end{tabular}

\begin{tabular}{|c|c|c|c|}
\hline $\mathrm{R}$ & $\mathrm{R}^{2}$ & F-value & $\mathrm{p}$-value \\
\hline .313 & .098 & 8.495 & .005 \\
\hline
\end{tabular}

\subsection{Predictors of Conceptual Understanding}

Table 8 summarizes the multiple regression results on the independent variables, critical thinking skills and the total epistemological beliefs in chemistry scores, as the dependent variable, the conceptual understanding score. The positive coefficient means that as the value of the critical thinking skills score increases, the predicted value of the conceptual understanding score likewise increases. Data reveal that critical thinking with a standardized beta $\beta$ coefficient of 0.456 is a highly significant $(p<.000)$ predictor of conceptual understanding. This finding suggests that the model accounted for approximately $21.3 \%$ of the total variance on conceptual understanding in chemistry. The generated F-value of 10.429 at $\mathrm{p}<0.000$ tells that the model is highly significant. On the other hand, internal beliefs subscale is a negative significant predictor of conceptual understanding. This means as the more students rely on their internal beliefs the lower is their concept understanding score. May and Etkina reported that epistemological beliefs are related to forms of academic performance such as conceptual understanding [13].

Table 8

Multiple regression results: Critical thinking skills and students' epistemological beliefs in chemistry as predictors of conceptual understanding

\begin{tabular}{|l|l|l|l|}
\hline & \multicolumn{1}{|c|}{$\beta$} & \multicolumn{1}{|c|}{-value } & $\mathrm{p}$-value \\
\hline (Constant) & & -.176 & .861 \\
\hline Post CTA & .456 & 4.494 & .000 \\
\hline Post EBCQ & .042 & .412 & .681 \\
\hline
\end{tabular}

\begin{tabular}{|c|c|c|c|}
\hline $\mathrm{R}$ & $\mathrm{R}^{2}$ & $\mathrm{~F}$-value & $\mathrm{p}$-value \\
\hline .462 & .213 & 10.429 & .000 \\
\hline
\end{tabular}

The positive $\beta$ coefficient explains that a higher score on the critical thinking skills score would increase the value of the dependent variable, conceptual understanding score. This finding is in accord with the study of Cotton and averred that all thinking skills programs had positive effect on achievement and critical thinking is a positive predictor of achievement test scores in chemistry Marasigan [2] [12].

\subsection{Critical Thinking Subskills and Epistemological Subscale Beliefs in Chemistry as Predictors of Conceptual Understanding}

Results (Table 9) show that of the five (5) subskills of critical thinking score, only inference is a positive predictor of conceptual understanding As to the nine epistemological beliefs, the internal, empirical and theoretical beliefs subscales significantly contribute to students' understanding of chemistry concepts. The empirical and theoretical beliefs subscales are positive predictors of conceptual understanding which means that the more students rely on these beliefs the higher would be their scores in the concept understanding test. On the other hand, internal beliefs subscale is a negative significant predictor of conceptual understanding. This means as the more students rely on their internal beliefs the lower is their concept

Table 9

\section{Multiple regression results: Critical thinking subskills and epistemological subscale beliefs in chemistry as predictors of conceptual understanding}




\begin{tabular}{|l|c|c|c|}
\hline & $\beta$ & t-value & $\mathrm{p}$-value \\
\hline (Constant) & & 1.480 & .143 \\
\hline Inference & .353 & 3.576 & .001 \\
\hline Internal & -.270 & -2.811 & .006 \\
\hline Empirical & .218 & 2.200 & .031 \\
\hline Theoretical & .196 & 2.011 & .048 \\
\hline
\end{tabular}

\begin{tabular}{|c|c|c|c|}
\hline $\mathrm{R}$ & $\mathrm{R}^{2}$ & $\mathrm{~F}$ & $\mathrm{p}$-value \\
\hline .577 & .333 & 9.353 & .000 \\
\hline
\end{tabular}

understanding score. May and Etkina reported that epistemological beliefs are related to forms of academic performance such as conceptual understanding [13].

\section{Conclusions}

The following conclusions are drawn from the findings of the study:

1. The students manifest sophisticated, theoretical, empirical and perceptual beliefs as to the nature of chemistry knowledge. On the nature of knowing the common beliefs among them are: external and social as knowledge belief sources and justification of beliefs on knowing chemistry.

2. Students of different ethnicity do not differ in their epistemological beliefs both in the nature of chemistry knowledge and nature of knowing.

3. Students exposed to the epistemologicalenhanced instruction (EEI) scored significantly higher in the total epistemological beliefs in chemistry scale than the students exposed to the lecture method of instruction (LMI). More specifically, perceptual, naïve, external and justification beliefs subscales contributed to the significant difference in the score.

4.The theoretical beliefs significantly predict critical thinking skills.

5. The empirical and theoretical beliefs subscales are significant positive predictors of students' conceptual understanding. The internal source subscale is a negative predictor of conceptual understanding.

6. The students' critical thinking skills specifically, the inference sub skill, influenced their understanding of chemistry concepts.

\section{References}

[1] Ashkenazi, Guy. Probing Students' Understanding of Chemical Concepts. Construction of a General Chemistry Concept Inventory through the use of Interactive Lecture Demonstrations. Retrieved August 18, 2006, http://www. fh.hiij.ac.il/ guy/project.

[2] Cotton, Kathleen. (2001 b) Teaching Thinking Skills. School Improvement Research Series. http://www.nwrel. org/scpd/sirs/6/cu11.html

[3] Elby, Andrew. (2002). Helping physics students how to learn. http://www2.physics.umd.edu/ elby/papers/ epist1/epist_curric.htm).

[4] Hofer, B. (1994). Epistemological Beliefs and First Year College Students; Motivation and in Different Instructional Context; Paper presented at the $102^{\text {nd }}$ Annual Meeting of Association of Psychological Association, Los Angeles, 12-16 August.

[5] Hofer, B. K. and Pintrich, P.R. (2002) (Eds). Personal Epistemology: The psychology of beliefs about knowledge and knowing. New Jersey. Lawrence Erlbaum.

[6] Hofer, B. K. (2000). Dimensionality and disciplinary differences in personal epistemology. contemporary Educational Psychology, 25. 378-405.

[7] Hofer, B. K. \& Pintrich, P. R. (1997). The development of epistemological theories: Beliefs about knowledge and knowing and their relation to learning. Review of Educational Research 87.

[8] Jheng, J.C. J. Johnson and Anderson R.C. (1993). Schooling and students' epistemological beliefs about learning. Contemporary (Eds.). Personal Epistemology; The Psychology of beliefs about knowledge and knowing (pp. 37-61). New Jersey. Lawrence Erlbaum.

[9] Kim, Tina Lim Swee. (2006). Science Epistemological Beliefs of Form Four Students and Science Achievement Using Web-Based Learning. Retrieved November 23, 2006. http://www.uum.edu.my / fskp/seminar/151m3/fullpaper/tinalim-fullpaper.pdf.

[10] Leach, John. Andy Hind, \& Jim Ryder (2003). Designing and Evaluating Short Teaching Interventions about the Epistemology of Science in High School Classroom. Journal of Research in Science Teaching. Vol. Wiley Periodicals, Inc.

[11] Lederman,N,G.(1992).Students' and teachers conceptions of the nature of science: a review of the research. Journal of Research in Science Teaching, 29331-339

[12] Marasigan, Arlyne C. (2007). Modified Learning Approach, Student Achievement, Critical Thinking and Attitude in Chemistry. Unpublished Master's Thesis. College of Education, U.P. Diliman, Quezon City. 
[13] May, David and Eugenia Etkina. (2002). College physics students epistemological self- reflection and its relationship to conceptual learning. American Journal of Physics.

[14] Millwood, Kelli A. and William A. Sandoval. (2003). A Comparison of Students' Beliefs about School Science and Professional Science. A paper presented at Annual Meeting of the American Educational Research Association. San Diego, CA. Retrieved April 4, 2006. http://www.gseis.ucla..edu/faculty/sandoval/pdf/ Millwood AERO4.pdf.

[15] Pintrich, P.R. (2002). Future challenge and directions for theory and research on personal epistemology. In B. K. Hofer and P.R. Pintrich, (Eds). Personal epistemology: The Psychology of beliefs about knowledge and knowing (pp.103-118). Mahwah, N.J. Lawrence Erlbaum Associates.

[16] Radigan, Judy (2001). Personal Epistemological Beliefs Expressed in a Classroom. Oxford. UK.

[17] Redish, E. F. \& David Hammer. (2000). Learning How to Learn Science: Physics for bioscience majors. Proposal to the NSF ROLE competition.

[18] Sandoval, William A.(2001). Students' uses of data as evidence in scientific explanations. A Paper presented at the Annual Meeting of the American Educational Research Association, Seattle, WA April 19-23, 2001. Retrieved 4/22/06 from http/www.gseis.icla.edu/faculty/sandoval/pdf/sandovalaera01. pdf.

[19] Tolhurst, Denise (2004). The Influence of Websupported Independent Activities and Small GroupWork on Students' Epistemological Beliefs. Retrieved November 18, 2005, http: //crpit.com/ confpapers/CRPITV30Tolhurst.pdf.

[20] Tsai, Chin Chung.(2000). Relationships between students' scientific epistemological beliefs and perceptions of constructivist learning environments. Educational Research,42 (2), 193-205. 